\title{
PENINGKATAN HASIL BELAJAR SISWA KELAS XI SMA NEGERI 4 AMBON PADA MATERI IRISAN KERUCUT DENGAN MENGGUNAKAN MODEL PEMBELAJARAN KOOPERATIF MELALUI MEDIA PEMBELAJARAN CAI (COMPUTER ASSISTED INSTRUCTION) BERBANTUAN SOFTWARE GEOGEBRA
}

\author{
John Lekitoo' ${ }^{1}$, La Moma ${ }^{2}$, Darma Andreas Ngilawajan ${ }^{3}$ \\ ${ }^{1,2,3}$ Program Studi Pendidikan Matematika Fakultas Keguruan dan Ilmu Pendidikan,Universitas Pattimura \\ Jalan Ir. M. Putuhena, Ambon, Indonesia \\ e-mail: ${ }^{1}$ johnlekitoo@gmail.com
}

\begin{abstract}
Abstrak
Tujuan penelitian untuk meningkatkan hasil belajar siswa kelas XI SMA Negeri 4 Ambon pada materi irisan kerucut dengan menggunakan model pembelajaran kooperatif melaluimedia pembelajaran CAI (ComputerAssistedInstruction) berbantuan software geogebra. Siswa dibagi atas kelompok kecil terdiri dari 3 kelompok yang beranggotakan 5-6 siswa yang berkemampuan bervariasi. Hasil penelitian menunjukkan bahwa dengan menggunkan model pembelajaran kooperatif melalui media pembelajaran Computer Assisted Instruction (CAI) berbantuan software geogebra, terdapat peningkatkan hasil belajar siswa kelas XI MIA SMA Negeri 4 Ambon.
\end{abstract}

Kata Kunci: Aktivitas Belajar, Kemandirian Belajar, Pengaruh langsung, Pengaruh tidak langsung, Model Persamaan Struktural (SEM)

\section{IMPROVEMENT OF LEARNING OUTCOMES GRADE XI STUDENTS OF SMA NEGERI4 AMBON IN THE CONE SLICE MATERIAL USING COOPERATIVE LEARNING MODEL THROUGH CAI (COMPUTER ASSISTED INSTRUCTION) LEARNING MEDIA ASSISTED BY GEOGEBRA SOFTWARE}

\begin{abstract}
Theaims of this study is to improve the learning outcomes of grade XI students of SMA Negeri4 Ambon in cone slice material using a cooperative learning model through CAI (Computer Assisted Instruction) learning media assisted by geogebrasoftware. Students divided into small groups ( 3 groups) with each groups consist of 5-6 students who have varied abilities. The results showed that by using the cooperative learning model throughlearning media CAI (Computer Assisted Instruction)assisted by geogebrasoftware, there was an increase in the learning outcomes of grade XI MIA students at SMA Negeri 4 Ambon
\end{abstract}

Keywords: Learning Activities; Learning independence; direct influence; Indirect influence; Structural Equation Model (SEM)

\section{Pendahuluan}

Dalam kehidupan manusia, bidang pendidikan merupakan bidang yang sangat penting bagi pembangunan sumber daya seutuhnya.Hal ini menuntut manusia harus leluasa menggunakan kemajuan teknologi yang telah disediakan di abad ke-21 ini.Abad ke-21 ini menekankkan kepada dunia pendidikan sekarang agar lebih relevan sejalan dengan peradaban dunia sekarang ini.
Pendidikan bertujuan untuk mencerdaskan kehidupan bangsa, maka tak heran jika pendidikan berperan penting dalam kehidupan manusia. Pendidikan secara formal diajarkan di tingkat jenjang Sekolah baik dari Sekolah Dasar sampai dengan Perguruan Tinggi. Terlepas dari semua itu pada kenyataannya mutu pendidikan di Indonesia masih sangat kalah dengan Negara-negara lain, sehingga pendidikan di Indonesia harus diperbaharui. 
Pembaharuan adalah hal yang lumrah dalam dunia pendidikan dan pembelajaran. Setiap saat terjadi perubahan dalam berbagai hal seperti teori belajar dan pembelajaran, orientasi pendidikan, kebutuhan dunia usaha dan dunia industri, dan sebagainya.Guru yang mempersiapkan pembaharuan pembelajaran, sesungguhnya telah mempersiapkan hari besok yang baik bagi anak didiknya (Ratumanan, 2015: 20).

Matematika adalah salah satu disiplin ilmu yang mempengaruh kehidupan manusia.Siregar dan Marsigit (2015: 225) berpendapat bahwa matematika adalah pengetahuan terstruktur yang terorganisasikan, aksioma-aksioma, sifat-sifat, dan seni sehingga matematika dapat disebut juga ilmu dekdutif.Oleh karena objek matematika yang abstrak dan sarat dengan simbol maupun istilah matematis seringkali membuat siswa merasa sulit untuk mempelajari matematika.

Dalam observasi dan wawancara yang dilakukan peneliti dengan guru matematika dan para siswa di Sekolah Menegah Atas (SMA) Negeri 4 Ambon, terlihat bahwa kebanyakan siswa di sekolah tersebut masih kurang paham mengenai fungsi kuadrat.Hal ini ditunjukkan lewat hasil tugas rumah dan hasil ulangan mereka yang tidak memenuhi nilai ketuntasan. Diasumsikan bahwa pengaruh dari minimnya penguasaan materi geometri, berdampak pada minimnya penguasaan materi fungsi kuadrat, hal ini dilihat dari cara menentukan dan menggambar fungsi parabola. Hal ini berakibat bagi siswasiswa yang berada pada kelas XI Matematika dan Ilmu Alam (MIA) yang nantinya di semester genap akan mempelajari materi irisan kerucut.

Permasalahan lain yang juga didapatkan ketika melakukan observasi dan wawancara adalah model pembelajaran yang masih berpusat pada guru, sehingga mengakibatkan proses interaksi antara siswa satu dengan yang lain untuk menukarkan infomasi yang diterima sangat kurang. Salah satu model pembelajaran yang harus dicoba adalah model pembelajaran kooperatif yang mengutamakan belajar kelompok.Hal ini dimaksudkan agar siswa-siswa tersebut mampu untuk menukarkan informasi yang mereka terima dan miliki.

Materi irisan kerucut sangat membutuhkan konsep geometri yang mendalam dari siswa-siswa tersebut agar mengetahui bagaimana irisan kerucut tesebut dibentuk dan apa saja jenis-jenis irisan kerucut tersebut. Sehingga, perlu proses belajar mengajar yang membuat siswa dengan mudah memahami konsep geometri lewat materi irisan kerucut.

Salah satu pembelajaran berbasis teknologi yang dapat digunakan guru adalah CAI (Computer Assited Instruction).CAI dapat diterapkan tanpa koneksi internet maupun koneksi antar server/komputer.CAI adalah bentuk penyajian bahan-bahan pembelajaran dan keahlian atau keterampilan dalam satuan unit-unit kecil yang menempatkan komputer sebagai piranti sistem pembelajaran, sehingga mudah dipelajari dan dipahami oleh siswa (Rusman, 2012: 154). Pembelajaran dirancang di program systemCAI. Media tersebut dapat dibuat dari berbagai software yang nantinya memperdalam konsep geometri pada siswa.

Software geogebra adalah salah satu program dinamis yang memiliki fasilitas untuk menvisualisasikan atau mendemonstrasikan konsep-konsep matematika serta sebagai alat bantu untuk mengkonstruksi konsep-konsep matematika (Syahbana, 2016: 2). Software geogebra adalah salah satu software yang sangat membantu dalam proses belajar mengajar yang berkaitan dengan konsep geometri secara keseluruhan. Dengan demikian salah satu alternatif solusi untuk membantu siswa dalam proses pembelajaran mengusai konsep geometri khususnya materi irisan kerucut adalah merancang pembelajaran dengan menggunakan software geogebra.

Berdasarkan uraian di atas, maka peneliti tertarik untuk melakukan kajian Peningkatan Hasil Belajar Siswa Kelas XI SMA Negeri 4 Ambon Pada Materi Irisan Kerucut Dengan Menggunakan Model Pembelajaran Kooperatif Melalui Media Pembelajaran CAI (ComputerAssistedInstruction) Berbantuan Software Geogebra

\section{Metode Penelitian}

\subsection{Tipe Penelitian}

Tipe penelitian yang digunakan dalam penelitian ini adalah penelitian kualitatif dengan model Penelitian Tindakan Kelas (PTK). Menurut Tutuhatunewa dan Laurens (2016: 4), PTK adalah suatu jenis penelitian reflektif yang melibatkan suatu tindakan (treatment) yang diberikan pada siswa.Selanjutnya Suharsimi (Tutuhatunewa \& Laurens, 2016: 15) menggambarkan model PTK dalam bagan sebagai berikut. 


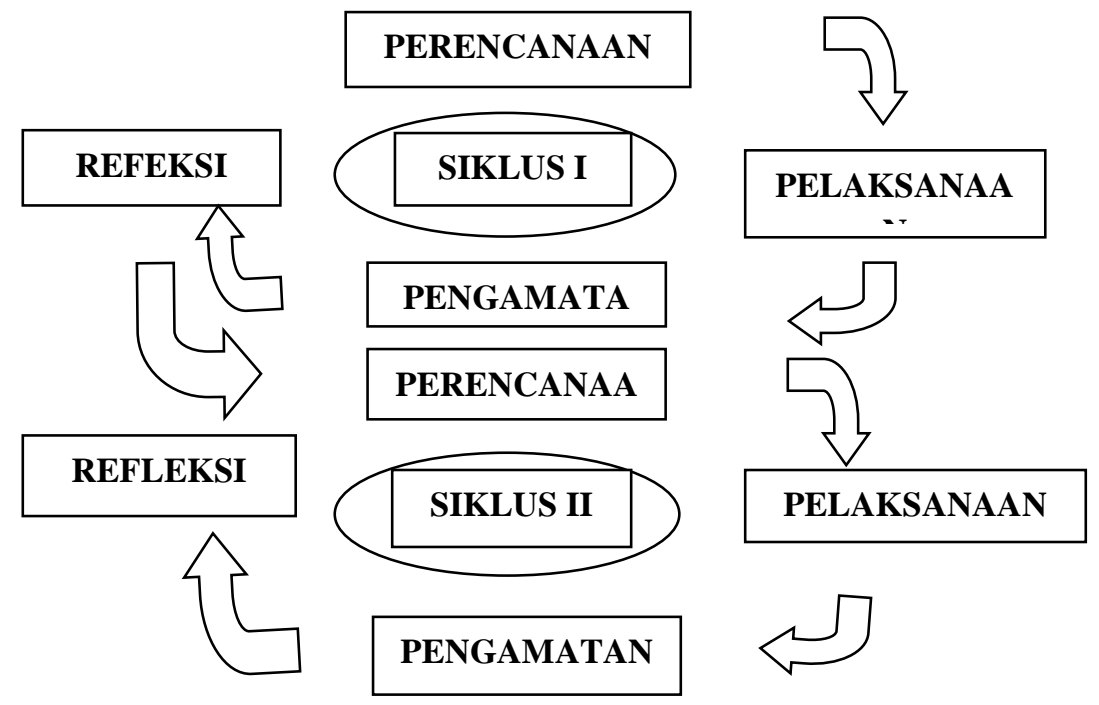

Gambar 1. Model PTK, Suharsimi (Tutuhatunewa \& Laurens, 2016: 15)

\subsection{Setting Penelitian}

Penelitian ini dilaksanakan di SMA Negeri 4 Ambon, Kota Ambon, Provinsi Maluku. Pada semester genap tahun ajaran 2017/2018, pada tanggal 23 januari 2018 sampai dengan 23 februari 2018.

\subsection{Subjek Penelitian}

Subjek dalam penelitian adalah siswa kelas XI MIA1 SMA Negeri 4 Ambon tahun ajaran 2017/2018 yang berjumlah 36 siswa, sampai akhir penelitian hanya 33 siswa yang datanya lengkap dan data 33 siswa inilah yang dianalisis.

\subsection{Sumber Data}

Sumber data pada penelitian ini adalah siswa kelas XI MI A1 SMA Negeri 4 Ambon tahun ajaran 2017/2018, dan guru yang mengajar matematika di kelas tesebut.

\subsection{Teknik Pengumpulan Data}

Teknik pengumpulan data pada penelitian ini adalah sebagai berikut.

a. Tes

Tes dilakukan oleh guru secara mandiri kepada siswa pada setiap akhir siklus, dengan tujuan untuk mengetahui hasil belajar siswa setelah melakukan pembelajaran matematika dengan menggunakan model kooperatif melalui media pembelajaran CAI berbatuan software geogebra.

b. Obervasi

Observasi yang dilakukan dalam penelitian ini adalah melakukan pengamatan terhadap guru dalam melaksanakan proses pembelajaran dengan menggunakan model kooperatif melalui media pembelajaran CAI berbatuan software geogebra dan terhadap siswa dalam aktivitas belajar dalam kelompok. Observasi ini dipandu dengan lembar observasi yang telah dibuat dan dalam penelitian ini dibentuk 6 kelompok dimana 3 kelompok yang beranggotakan 5 siswa yaitu kelompok II, V dan VI sedangkan kelompok I, III dan IV memiliki anggota yang lengkap yaituberjumlah 6 . Ada 3 observer dalam penelitian ini yaitu guru (DR) mengamati guru (NS), peneliti mengamati aktivitas kelompok I, II dan III, serta observer (AL) yang merupakan teman mahasiswa peneliti mengamati kelompok IV, V dan VI.

\subsection{Teknik Analisa Data}

Data dari hasil penelitian ini diolah dengan menggunakan teknik analisis data kuantitatif dan analisis data kualitatif.Analisis data kuantitatif menggunakan statistik deskriptif. Data yang dianalisa adalah hasil belajar siswa terhadap materi yang diajarkan dan respon siswa terhadap pembelajaran yang menggunakan model pembelajaran kooperatif melalui media pembelajaran CAI (Computer Assisted Instruction) berbantuan software geogebra. Untuk mengetahui hasil belajar siswa yaitu ketuntasan siswa terhadap materi pelajaran maka rumus yang digunakan (Purwanto, 2009: 12), sebagai berikut.

Hasil Belajar $=\frac{\text { Skor yang diperoleh }}{\text { Skor total }} \times 100$

Selanjutnya dari hasil presentasi kemudian dikualifikasikan tingkat penguasaan siswa berdasarkan Kriteria Ketuntasan Minimal (KKM) yang telah ditentukan di SMA Negeri 4 Ambon, yaitu 
Tabel 1. Kriteria Ketuntasan Minimal (KKM)

\begin{tabular}{cc}
\hline Nilai & Keterangan \\
\hline$\geq 70$ & Tuntas \\
$<70$ & Belum Tuntas \\
\hline Sumber: SMA Negeri 4 Ambon
\end{tabular}

Secara klasikal untuk menghitung persentase ketuntasan siswa terhadap materi pelajaran menggunakan rumus:

Persentase Ketuntasan Klasikal

$$
=\frac{\text { jumlah siswa tuntas }}{\text { jumlah seluruh siswa }} \times 100 \%
$$

Suryosubroto (2009: 77) mengatakan, bahwa syarat suatu pembelajaran dikatakan tuntas secara individu maupun klasikal jika siswa tersebut mencapai skor minimal $65 \%$.Analisis data kualitatif dianalisis dengan model analisis interaktif yang dikembangkan oleh Miles dan Huberman (Tutuhatunewa \& Laurens, 2016: 52), yaitu Reduksi Data, Paparan Data, Penarikan Kesimpulan.

\section{Hasil dan Pembahasan}

\subsection{Hasil}

Jumlah keseluruhan siswa pada kelas tersebut berjumlah 36 siswa yang dibagi dalam 6 kelompok, namun pada akhir penelitian yang dilakukan hanya 33 siswayang memiliki data lengkap. Dengan demikian ada 3 kelompok yang beranggotakan 5 siswa yaitu kelompok II, V dan VI sedangkan kelompok I, III dan IV memiliki anggota yang lengkap yaitu berjumlah 6 .

Telah dikemukakan bahwa dalam penelitian ini dilakukan 2 (dua)kali tes pada setiap akhir siklus. Setiap tes dihitung nilai setiap siswa untuk mengetahui bagaimana ketuntasan siswa setiap siklus.

a. Hasil tes pada siklus II menunjukkan bahwa adanya peningkatan dari siklus I yaitu dari 16 siswa yang tuntas dari keseluruhan siswa pada siklus I atau $48,48 \%$ siswa menjadi 27 siswa yang tuntas pada siklus II atau $81,82 \%$ siswa. Ini berarti hasil yang diperoleh sudah memuaskan, karena melebih standar persentase ketuntasan yang ditetapkan yaitu $\geq 65 \%$.

b. Siswa sudah aktif dalam kegiatan diskusi kelompok, dan setiap kelompok sudah baik dalam mempresentasikan hasil pekerjaan mereka dan menanggapi hasil dari kelompom lain, dilihat dari semua kelompok.
Adapun peningkatan hasil belajar siswa dari siklus I dan siklus II pada penelitian ini, disajikan dalam diagram berikut.

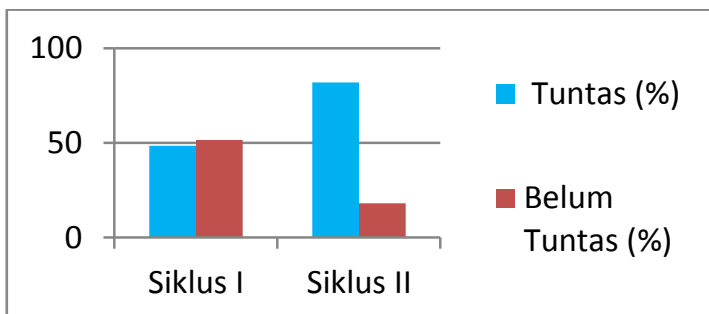

Gambar 2. Diagram Persentase Ketuntasan Belajar

\subsection{Pembahasan}

\section{Siklus I}

Pada pembelajaran pada siklus I belum sepenuhnya sesuai dengan apa yang diharapkan yaitu belum sesuai dengan model pembelajaran kooperatif melalui pembelajaran CAI berbantuan software geogebra. Kemudian pada siklus I guru kurang mengontrol aktivitas kelas dengan baik. Selain dari pada kontrol kelas yang kurang optimal dari guru, terdapat beberapa masalah yang didapati pada siklus I selama proses pembelajaran sebagai berikut:

a. Siswa dihadapkan dengan situasi yang baru yaitu pembelajaran kelompok berbasis komputer dengan bantuan software geogebra. Menurut Rohani (2010: 193) bahwa siswa yang memasuki situasi baru secara mendadak sering menimbulkan tekanan psikologis karena situasi yang lama sering membayangi mereka. Dengan demikian situasi baru tersebut membuat proses pembelajaran terhadap siswa semakin sulit dan lambat.

b. Siswa kurang aktif dalam kegiatan kelompok, dan kurang bertanya kepada guru ketika mendapatkan kesulitan, seperti yang terlihat pada kelompok II, V dan VI. Menurut Ratumanan (2015: 151) aktivitas siswa yang baik antara lain mengikuti penjelasan guru secara aktif, bekerja sama menyelesaikan tugas-tugas kelompok, memberikan penjelasan kepada teman kelompoknya, mendorong kelompok untuk berpartisipasi secara aktif, berdiskus, dan sebagainya. Oleh karean itu, keberhasilan terhadap tujuan pembelajaran harus menuntut siswa agar aktif bukan saja secara kerja individu tetapi juga secara kerja kelompok. 
c. Penggunaan media pembelajaran berupa software geogebra kurang optimal yang dilakukan guru. Menurut Rusman (2012: 162) ketiadaan atau kurang optimalnya pemberdayaan media pembelajaran dalam proses belajar seringkali membuat siswa tidak atau kurang memahami pelajaran yang diberikan guru. Hal ini membuat banyak manfaat yang ada dalam software geogebra yang tidak dipakai guru untuk menjelesakan materi pembelajaran, sehingga membuat siswa sulit untuk memahami materi pelajaran. Hasil penelitian Minarto (2017: 7) mengatakan bahwa dengan menggunakan media pembelajaran berbantuan software geogebra dengan baik memberikan dampak positif terhadap nilai prsetasi belajar siswa dalam pembelajaran matematika. Penggunaan software geogebra dengan tidak optimal sehingga mempengaruhi hasil tes siswa pada siklus I

d. Guru kurang memberikan penguatan berupa motivasi bagi siswa akan pentingnya belajar. Menurut Rusman (2012: 70), dengan memberikan penguatan kepada dimaksudkan untuk memberikan ganjaran atau membesarkan hati siswa agar mereka lebih giat berpartisipasi dalam interkasi pembelajaran. Salah satu tujuan memberi penguatan kepada siswa adalah merangsang dan meningkatkan motivasi belajar. Dalam proses belajar mengajar pada siklus I, sebagian besar siswa tidak menunjukkan antusias dalam meyelesaikan LKS yang dibagikan oleh guru dalam kelompok.

e. Penguasaan dan pengelolahan kelas yang kurang dari guru sehingga memberikan kesempatan bagi siswa untuk bercerita dan menggangu teman. Menurut Rusman (2012: 77), salah satu komponen mengelolah kelas dengan baik adalah mengembalikan kondisi belajar yang optimal agar tujuan dari pembelajaran tersebut dapat tercapai dengan baik. Hal ini mengakibatkan terjadi keributan di dalam kelas akibat lemahnya penguasaan dan pengelolahan kelas dari guru.

Beberapa masalah di atas tersebut membuat proses pembelajaran kurang berjalan dengan baik. Akibatnya siswa kesulitan dalam mengerjakan soal tes akhir siklus I. Melihat beberapa kelemahan tersebut dan juga hasil belajar siswa yang belum mencapai persentase ketuntasan, maka peneliti memutuskan untuk melanjutkan penelitian ini pada siklus II dengan merancang tindakan perbaikan dengan memperhatikan kelemahan yang ada pada siklus I.

\section{Siklus II}

Pada siklus II terlihat bahwa terjadi peningkatan hasil belajar siswa. Hal ini ditunjukkan dengan beberapa kelemahan yang ada pada siklus I tidak terlihat lagi di siklus II atau dengan kata lain guru sudah menerapkan model pembelajran kooperatif melalui pembelajaran CAI berbantuan software geogebra.Guru juga terlihat sudah dapat mengelolah kelas dengan baik.Bukan saja itu penggunaan software goegebra dalam fungsinya sebagai media pembelajaran juga sudah diberlakukan dengan baik oleh guru.

Siswa juga terlihat sangat serius dalam mengikuti proses pembelajaran di kelas, sehingga perilaku-perilaku yang tidak relevan tidak terlihat pada siklus II. Siswa juga aktif dalam melakukan diskusi kelompok dan mampu mepresentasikan hasil diskusi mereka dengan segala baik. Proses diskusi di dalam kelompok berjalan dengan sesuai yang diharapkan tidak terlepas dari kontrol guru yang terlihat ketika sedang berdiskusi guru berkeliling dan membimbing serta juga memberikan bantuan seperlunya bagi kelompok untuk menyelesaikan LKS yang ada dalam kelompok.

Berdasarkan hasil yang diperoleh dan peningkatan pada siklus II, maka dapat disimpulkan bahwa model pembelajaran kooperatif melalui pembelajaran CAI berbantuan software geogebra telah dilaksanakan oleh guru dengan baik dan pelaksanaan tindakan telah dilakukan dengan baik. Hal ini menunjukkan bahwa hipotesis tindakan telah dicapai yaitu ada peningkatan hasil belajar siswa kelas XI SMA Negeri 4 Ambon pada materi irisan kerucut dengan menggunakan model pembelajaran kooperatif melalui media pembelajaran CAI (Computer Assisted Instruction) berbantuan software geogebra.

Kelemahan Penelitian

Ada beberapa kelemahan dalam penelitian ini yaitu,

a. Penelitian ini dilaksanakan dalam 2 siklus dengan masing-masing siklus hanya 1 pertemuan saja.

b. Waktu penelitian ini dilakukan dalam periode 1 minggu, dikarenakan tatap muka mata pelajaran matematika minat di SMA Negeri 4 Ambon sebanyak 2 kali dalam 1 minggu.

\section{Kesimpulan}

Berdasarkan hasil dan pembahasan maka dapat disimpulkan bahwa dengan menggunkan 
model pembelajaran kooperatif melalui media pembelajaran Computer Assisted Instruction (CAI) berbantuan software geogebra, maka dapat meningkatkan hasil belajar siswa kelas XI MIA SMA Negeri 4 Ambon. Hal ini terlihat dari hasil tes siklus I yang memperoleh kriteria ketuntasan minimal (KKM) atau memperoleh nilai $\geq 70$ sebanyak 16 siswa dengan persentase $48,48 \%$,. Kemudian pada siklus II siswa yang memperoleh kriteria KKM atau siswa yang memperoleh nilai $\geq$ 70 sebanyak 27 siswa dengan persentase $81,82 \%$. Berdasarkan ketuntasan pada siklus I dan siklus II, maka terjadi peningkatan yang terjadi dari siklus I ke siklus II sebesar 33,34\%.

Berdasarkan kesimpulan diatas, peneliti memberikan beberapa saran sebagai berikut:

a. Guru diharapkan harus lebih kreatif dalam melakukan pembelajaran dengan siswa, terkait dengan pemilihan model pembelajaran dan menggunakan media yang telah disediakan pada abad ke-21 ini.

b. Penggunaan model pembelajaran kooperatif melalui pembelajaran CAI berbantuan software geogebra harus dikembangkan dengan baik, bukan saja pada materi yang berkaitan dengan konsep geomtri saja tetapi juga materi matematika yang berkaitan dengan aljabar juga.

\section{Daftar Pustaka}

Minarto.2017. Penggunaan Aplikasi Geogebra Sebagai Media Pembelajaran Dalam Upaya Meningkatkan Prestasi Belajar Matematika Pada Materi Fungsi Kuadrat. Bayuwangi: eJurnal Mitra Pendidikan. Vol. 1, No. 3.Hal.110.

Ratumanan, T. G. 2015. Inovasi Pembelajaran (Mengembangkan Kompetensi Peserta Didik Secara Optimal). Yogyakarta: Penerbit Ombak.

Rohani. 2010. Pengolahan Pengajaran. Jakarta: PT Rineka Cipta.

Rusman. 2012. Belajar dan Pembelajaran Berbasis Komputer. Bandung: Penerbit Alfabeta.

Siregar, N. C dan Marsigit.2015. Pengaruh Pendekatan Discovery Yang Menekankan Aspek Analogi Terhadap Prestasi Belajar, Kemampuan Penalaran, Kecerdasan Emosional Spiritual.Yogyakarta:Jurnal Riset Pendidikan Matematika,Vol 2. No 2, Hal. 224234.

Syahbana, A. 2016.Belajar Menguasai Geometri: Program Aplikasi Pembelajaran Matematika. Palembang: Noerfikri Offset.

Tutuhatunewa, E dan Laurens, T. 2016. Penelitian Tindakan Kelas. Yogyakarta: Pensil Komunika

\author{
Tanudjaja, M, 2011. Aku Cerdas Karena Tidak Bisa \\ Matematika. Jakarta: Pt. Gramedia Pustaka \\ Utama. \\ Yamin, 2010.Strategi Pembelajaran Berbasis \\ Kompetensi. Jakarta: Press..
}

